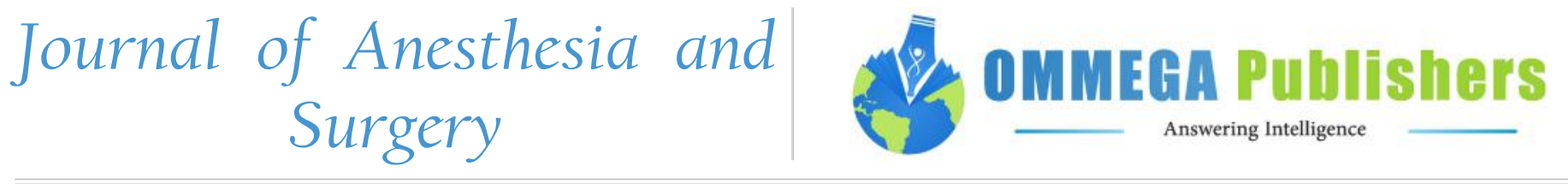

Review Article

\title{
Prevention of Postoperative Pulmonary Complications-Multidisciplinary Approach
}

\author{
Surjya prasad Upadhyay ${ }^{*}$, Ulka Samanth ${ }^{1}$, Sudhakar Seth Tellicherry ${ }^{1}$, Gautam kumar Lahiri², \\ Partha Pratim Saikia ${ }^{3}$, Piyush N Mallick ${ }^{4}$
}

${ }^{1}$ Specialist anaesthesiologist, NMC hospital DIP, Dubai, UAE

${ }^{2}$ Specialist General and Laparoscopic surgeon; NMC Hospital DIP, Dubai, UAE

${ }^{3}$ Specialist Anaesthesiologist, Life LineHospital, Dubai, UAE

${ }^{4}$ Consultant Anaesthesiologist; Al Zahra Hospital, Sarjah, UAE

*Corresponding author: Surjya Prasad Upadhyay, Specialist anaesthesiologist, NMC hospital DIP, Dubai, UAE, Tel: 00971554078445; E-mail: run77in@yahoo.com

\begin{abstract}
Postoperative pulmonary complications (PPC) substantially increases the risk of morbidity, mortality, length of hospitalisation and has significant financial implications. Risks of postoperative pulmonary complications can be broadly divided into patient related, procedure related, anaesthesia related and postoperative care related. The prevention of PPC requires comprehensive multidisciplinary approach that include preoperative risk stratification and optimizations, intra-operative lung protective strategies, greater utilization of regional analgesia and avoidance of opioid analgesia, balancing intravenous fluid, minimising blood and blood product transfusion, fast tracking protocol for enhanced recovery, vigilance monitoring, physiotherapy and lung expansion manoeuvres including use of non-invasive ventilation in selected patients and other supportive care such as nutritional support, glycemic control, selective gastric drainage, thrombo-prophylaxis and early empirical antibiotic therapy in suspected infection and sepsis.
\end{abstract}

Keywords: Postoperative; Pulmonary complications; Acute lung injury; Lung protection; Multi-modal; Multidisciplinary

\section{Introduction}

Postoperative pulmonary complication (PPC) accounts for substantial increase in morbidity and mortality following anaesthesia and surgery. PPC ranges from simple atelectasis to frank pneumonia to Acute Lung Injury (ALI) or Acute Respiratory Distress Syndrome (ARDS ${ }^{[1-5]}$. ALI/ARDS are the extreme severe form of PPC which carries higher mortality, sometime exceeding $45 \%$ in certain surgical populations $\mathrm{s}^{[4,5]}$. The peri-operative period is an important period where many clinical and therapeutic strategy can be applied as preventive approach to reduce PPC. Early diagnosis of at risk group and proper timely interventions can both reduce the incidences and severity of PPC.

This review is aimed at addressing some of the important issues or risk factors for PPC in adults and their prevention through evidence based interventions in peri-operative period.

\section{General Anaesthesia and Pulmonary Physiology}

Induction of GA results in loss of respiratory muscle tone. The loss of supporting muscle tone promote the reduction in lung volume and onset of atelectasis; more than $90 \%$ patients under general anaesthesia developed some form of atelectasis and this atelectasis may persist beyond $24 \mathrm{hrs}$ in more than $50 \%$ and may in some
Citation: Upadhyay, S.P., et al. "Prevention of Postoperative Pulmonary Complications-Multidisciplinary Approach. (2015) J Anesth Surg 2(2): 46-53.

\section{Received date: March 13, 2015 \\ Accepted date: June 23, 2015 \\ Published date: June 26, 2015}

last up to week ${ }^{[6,7]}$. These effects are more evident in patients undergoing thoracic or upper abdominal surgery which can cause reduction in vital capacity by $50 \%$ and functional residual capacity (FRC) by $30 \%{ }^{[8]}$. The development of atelectasis is the primary event in the pathogenesis of PPC such as hypoxaemia, pulmonary infection, postoperative ALI or ARDS ${ }^{[7-14]}$. Three types of atelectasis are described based on the mechanisms of atelectasis; compression, absorption and loss of surfactant atelectasis. General anaesthesia (GA) is implicated in the development of all the three types of atelectasis ${ }^{[6,10,11]}$.

Following upper abdominal and thoracic surgery, the respiratory mechanics changes, patients tend to breath small tidal volume with rapid rate to maintain the adequate minute ventilation (rapid shallow breathing) and poor coughing effort due to dynamic pain ${ }^{[8]}$. This altered breathing patterns in addition to the residual effects of anaesthesia, impaired mucociliary clearance and coughing contribute to the retention of secretion and postoperative pneumonia. These effects are complicated by patient co-existing general debility 
or pulmonary illness or conditions such as smoking and acute physiological alteration in fluid electrolyte balance. Numerous studies and systemic reviews have been conducted to quantify the risk factors for predicting the PPC. Broadly these factors can be categorised into patient related factors, procedure related, anaesthesia related and postoperative care related.

\begin{tabular}{|c|c|c|c|}
\hline \multicolumn{4}{|c|}{ Important factors of Postoperative pulmonary complications } \\
\hline Patient related & $\begin{array}{l}\text { Procedure } \\
\text { Related }\end{array}$ & $\begin{array}{l}\text { Anaesthesia } \\
\text { Related }\end{array}$ & Postoperative \\
\hline $\begin{array}{l}\text { Age } \\
\text { Obesity } \\
\text { Obstructive } \\
\text { Sleep Apnea } \\
\text { Chronic } \\
\text { Obstructive Pul- } \\
\text { monary Disease } \\
\text { /asthma } \\
\text { Pulmonary } \\
\text { Hypertension } \\
\text { Interstitial lung } \\
\text { diseases } \\
\text { Respiratory } \\
\text { Tract Infection } \\
\text { Smoking/alco- } \\
\text { holism } \\
\text { General debility } \\
\text { Immunity }\end{array}$ & $\begin{array}{l}\text { Site of incision } \\
\text { Thoracic/ab- } \\
\text { dominal } \\
\text { Invasive sur- } \\
\text { gery } \\
\text { Duration of } \\
\text { surgery } \\
\text { Fluid and blood } \\
\text { loss }\end{array}$ & $\begin{array}{l}\text { Anaesthesia } \\
\text { technique } \\
\text { Regional Vs GA } \\
\text { Mechanical } \\
\text { ventilation } \\
\text { Fluid balance } \\
\text { Use of blood } \\
\text { product } \\
\text { Hyperoxia/hy- } \\
\text { poxia } \\
\text { Analgesic } \\
\text { technique }\end{array}$ & $\begin{array}{l}\text { Monitoring } \\
\text { Postoperative } \\
\text { Analgesia } \\
\text { Early mobili- } \\
\text { sation } \\
\text { Physiotherapy } \\
\text { Lung expansion } \\
\text { techniques } \\
\text { Nutritional } \\
\text { support } \\
\text { Selective na- } \\
\text { so-gastric Tube } \\
\text { Thrmboprophy- } \\
\text { laxis } \\
\text { Glycemic } \\
\text { control } \\
\text { Judicial Antibi- } \\
\text { otic use }\end{array}$ \\
\hline
\end{tabular}

\section{Patient Related Factors}

Important patient related factors can be described as follow

\section{Age}

Elderly patients have decreased overall organ reserve, altered physiology of organs, and may have multiple associated co-morbid conditions. Studies have shown that age is an independent predictor of postoperative pulmonary complica$\operatorname{tion}^{[9,15,16]}$.

\section{Obesity}

Body Mass Index (BMI) above 35 is associated with many cardio-pulmonary changes such as sleep apnoea, atelectasis, obesity hypoventilation syndrome, pulmonary hypertension, cor-pulmonale and hypercapnic respiratory failure. Although the association of obesity and PPC is well known ${ }^{[17-19]}$, some studies failed to show the direct correlation between obesity and $\mathrm{PPC}^{[20-}$ ${ }^{22}$. Recent studies have shown that BMI above 35 is linearly associated with increasing PPC; but such correlation is not evident in patients with BMI less than $35^{[23,24]}$. There is $30 \%$ chances of developing PPC after abdominal surgery in patients with BMI of 40 and above ${ }^{[25]}$.

\section{General Health and immunity}

Poor functional status, general debilitated state, low albumin level, significant weight loss are also risk factors for PPC. Patients with immune compromised state are at risk for postoperative pneumonia and respiratory failure ${ }^{[15]}$.

\section{Personal habit: Smoking and Alcohol}

Smoking increases the risk of PPC more than 2 fold, and this risk remain elevated for up to 1 year even after cessa- tion of smoking ${ }^{[15,26-28]}$. Abrupt cessation of smoking can inhibit coughing and retention of secretion which leads to small airway obstruction. Ideally smoking should be stopped 8 week prior to schedule surgery; less than 8 week abstinence may be associated with higher incidence of pulmonary complication than those who continued to smoke ${ }^{[29]}$. A systemic review concluded that smoking cessation should be pursued in most patients even if it is very close to time of surgery, but the longer the abstinence period, the greater reduction in risk of pulmonary complications ${ }^{[30]}$. Smoking and alcoholism often co-exist in many patients. Alcoholism as such is also one of the risk factor for PPC and this risk is additive with concomitant smoking ${ }^{[3,31]}$.

\section{Obstructive sleep apnoea (OSA)}

Patients with OSA have higher incidences of PPC in the form of desaturation, atelectasis, respiratory failure, ALI/ ARDS requiring invasive ventilator support ${ }^{[26,32]}$. However, the incidence of severe PPC is relatively low irrespective of severity of OSA in patients already diagnosed pre-operatively ${ }^{[26]}$. It is the borderline patients or undiagnosed patients that pose a real threat. A recent survey by Auckley and Bolden has shown that significant number of surgical patients (24-41\%) have undiagnosed OSA and are at risk of serious PPC during the peri-operative period ${ }^{[33]}$.

\section{Pre-existing pulmonary pathology}

Obstructive lung diseases: Patients with Chronic Obstructive Pulmonary Disease (COPD) and Bronchial Asthma have higher incidences PPC in the peri-operative period ${ }^{[28,33-35]}$. For obstructive airway diseases there is no absolute prohibitive value of pulmonary function test that is contraindicative for surgery. Patients, who are symptomatic, have poor cough, limited exercise capacity or have acute exacerbation should be optimised before elective surgery. Well controlled Bronchial Asthma does not appear to have increased risk, but sub-optimal control of asthma does pose a risk for pulmonary complications ${ }^{[35]}$. As preoperative strategy, smoking cessation, bronchodilator and steroid, hydration, antibiotic and chest physiotherapy may help to optimise the underlying conditions. Use of steroid in peri-operative period in patients with COPD is debatable ${ }^{[36-38]}$. Inspiratory muscles training for 2-4 weeks prior to surgery in high-risk operations such as abdominal aortic aneurysm repair, CABG have shown significant reduction in $\mathrm{PPC}^{[39,40]}$. A few studies have demonstrated that intense inpatient pulmonary rehabilitation program significantly improved exercise tolerance and operability (lung resection) in comparison to their baseline status ${ }^{[41-43]}$.

Pulmonary hypertension (PHT): Pulmonary hypertension has been recognised as independent predictor of PPC after cardiac surgery ${ }^{[44-47]}$. Although, it is not included as independent risk factor in non-cardiac surgery, presence of pulmonary hypertension is associated with increased peri-operative cardiac and pulmonary complications ${ }^{[46-48]}$.

Interstitial Lung disease (ILD): ILD also pose increased risk for PPC. Thoracic surgery has been implicated in exacerbation of ILD. Low forced vital capacity, low diffusing capacity, ongoing exacerbation at the time of surgery and extent of surgical lung resection are linked with increased risk of postoperative 
exacerbation $^{[49,50]}$.

Respiratory Tract Infection (RTI): Recent or ongoing respiratory tract infection including bronchitis, pneumonia increases the risk of PPC. It is recommended to treat the underlying infection before proceeding with an elective surgery ${ }^{[51]}$.

\section{Procedure Related Risk Factors}

\section{Site of incision and duration of surgery}

The surgical incision site and its distance from the diaphragm are inversely related to the PPC. So, according to incision site, aortic aneurysm repair carries the highest risk followed by thoracic and upper abdominal surgeries; whereas, the lower abdominal and peripheral surgeries were associated with low incidence of PPC. Surgery lasting longer than 3-4 hrs is associated with higher incidence of PPC (40\%) in comparison to surgery lasting less than $2 \mathrm{hrs}$. $(8 \%)^{[15]}$.

\section{Invasiveness of surgical procedure}

Minimally invasive surgery or laparoscopic technique are associated with less postoperative pain, early ambulation and reduced risk for $\mathrm{PPC}^{[15,52-54]}$.

\section{Cardio-Thoracic surgery}

Major cardio-thoracic surgeries are associated with both local trauma and systemic inflammation because of cardio-pulmonary bypass(CPB $)^{[55,56]}$. PPC depends not only on the direct parenchymal damage due to manipulation or resection, but also on the pulmonary manifestation of systemic inflammatory response. Systemic inflammatory mediators cause damage to both capillary and alveolar endothelium disrupting the alveolar-capillary barrier, impairing gas exchange and causing extra-vascular fluid accumulation ${ }^{[57]}$. This extra-vascular water accumulation is the hallmark of $\mathrm{ALI}^{[58]}$. The main predictors of postoperative ALI in cardio-thoracic surgeries are pneumonectomy, excessive fluid loading, one lung ventilation, and cardiac surgery involving $\mathrm{CPB}^{[52,57,59-63]}$.

\section{Anaesthesia Related Risk Factors}

Anaesthestist have a great role in the protection of injured lung and the prevention of normal lung from injury during the peri-operative period. Despite the advancement in surgical and anaesthetic techniques, the incidence of PPC is remarkable. Proper anaesthetic management can prevent or ameliorate most of these injuries.

\section{Anaesthetic technique}

There are inconsistent data regarding pulmonary complication with spinal/epidural anaesthesia in comparison to general anaesthesia ${ }^{[64-66]}$. Patients who received general anaesthesia combined with neuraxial block for postoperative analgesia, were found to have lower incidences of postoperative pneumonia and respiratory failure likely due to less use of opioid in postoperative period ${ }^{[67,68]}$. These results suggest that addition of regional anaesthesia rather than avoidance of general anaesthesia may be the key to reducing pulmonary complications.

\section{Type of anaesthetic drugs}

Residual effects of long acting neuromuscular blocking drugs like pancuronium might remain in the immediate postoperative period, that can promote atelectasis and also increase the risk of aspiration. Short or intermediate acting muscle relaxant is preferred over long acting ones. Volatile anaesthetics may impair hypoxic pulmonary vasoconstriction causing ventilation-perfusion mismatch ${ }^{[69]}$.

\section{Mechanical ventilation}

The role of mechanical ventilation in the development on postoperative ALI has been debated for years. Aggressive mechanical ventilation has been recognised as one of the important risk factor for PPC ${ }^{55,58,59]}$. Use of small tidal volume (6-8 $\mathrm{ml} / \mathrm{kg}$ ) might protect the lung from mechanical insult of ventilation while maintaining adequate gas exchange ${ }^{[58]}$. Alveolar hyperinflation with cyclic stretching in prolonged mechanical ventilation may trigger lung injury ${ }^{[56,70]}$. The duration of mechanical ventilation might also play important role in post ventilation lung injury ${ }^{[71-73]}$. Intraoperative lung protective strategy in the form of low tidal volume, use of judicious PEEP and recruitment maneuvers in intermediate to high-risk patients undergoing major abdominal surgery was associated with improved clinical outcome and reduced health care utilization ${ }^{[74]}$. Such benefit of short term lung protective strategy for low risk patients is doubtful ${ }^{[75]}$. Although some studies do suggest beneficial effects of low tidal volume lung protective ventilator strategy even for short duration procedure for healthy lungs ${ }^{[76-80]}$.

\section{One lung ventilation}

Postoperative ALI after one lung ventilation in thoracic surgery is a distinctive entity. Four independent factors for primary ALI has been recognised. Intra-operative airway pressure, intravenous fluid replacement, pneumonectomy and preoperative alcohol abuse ${ }^{[53,81]}$.

\section{Transfusion related acute lung injury (TRALI)}

Transfusion Related Acute Lung Injury (TRALI) can develope in the peri-operative period ${ }^{[82,83]}$. The diagnosis of TRALI is basically a diagnosis of exclusion. Bilateral ALI associated within 6 hrs. of blood or blood product transfusion after excluding the other possible causes of ALI suggest TRALI ${ }^{[84]}$. The patho-physiology of TRALI is not yet clearly defined. The accepted model being immunologic injury where leucoagglutinating antibodies in the transfused plasma binds to recipient neutrophils and are subsequently sequestered in the lung activating complements and other inflammatory mediators resulting in endothelial damage, capillary leakage leading into frank ALI. The second postulated mechanism is that some biologically active mediator in blanked blood interact with lung tissue ${ }^{[85-88]}$. A delayed form of TRALI has been recognised that developed 6-72 hours after transfusion and is more apparent in critically ill or multiple trauma patient and is associated with higher mortality rate $^{[89]}$.

\section{Peri-operative fluid and ALI}

Alteration in haemodynamic, metabolic, endocrine and immunological functions that occur perioperatively have considerable effects in fluid balance and distribution. These changes alter the capillary permeability and promote transfer 
of intra-vascular fluid to the interstitial space, particularly the lung interstitial space that may progress from interstitial edema to frank pulmonary edema ${ }^{[90]}$. There is no universal or accepted definition of optimal, restrictive or liberal fluid therapy ${ }^{[91-94]}$. There is no clear agreement on the peri-operative fluid therapy. Direct association between liberal fluid administration and development of postoperative acute lung injury (ALI/ARDS) has been shown by many studies ${ }^{[94-98]}$.

\section{Inhalation anaesthetics and lung protection}

Recent studies have shown that volatile agent has immune modulating effects and protect the lung by inhibiting the expression of pro-inflammatory mediators such as IL-8, Il-10, TNF etc ${ }^{[99-103]}$. These exciting works indicates that volatile agents might have a significant role in attenuating the lung injury from host of insults; however, considerable work is needed to define their role on the extent of lung protection.

\section{Postoperative Strategy}

\section{Oxygen Therapy and PPC}

Oxygen is a two way sword. Both hypoxia and hyperoxia causes ischaemic re-perfusion type of injury ${ }^{[104,105]}$. The pulmonary changes that occur due to excess oxygen has been described as hyperoxic acute lung injury (HALI) ${ }^{[104-108]}$. The extent of lung injury in HALI depends on the duration and concentration of oxygen (above 50\%), existing lung pathology, concomitant infection and use of mechanical ventilation ${ }^{[106]}$. With the present concept of lung protective strategy in the form of PEEP, low tidal volume, minimal Fio2, the problem of HALI has been substantially reduced in recent times. Unlike the normal healthy lung, the threshold for HALI may be lowered in injured or diseased lung.

\section{Postoperative analgesia}

Adequate postoperative analgesia provide better patient comfort, help in initiation of early ambulation and hence reduces risk of deep venous thrombosis (DVT) and also improved the performance of lung expansion manoeuvres. Studies using epidural analgesia after thoraco-abdominal surgeries reported reduced postoperative complication than patients managed with conventional opioid analgesics ${ }^{[109-112]}$. Para-vertebral analgesia are associated with similar analgesic efficacy with fewer pulmonary complications than epidural analgesia ${ }^{[113]}$, however, other studies favour epidural analgesia ${ }^{[114,115]}$. With the advancement in knowledge and techniques of ultrasonography guided needle placement, varieties of truncal blocks such as para-vertebral, intercostal, transverse abdominals plane, rectus sheath and illio-inguinal/illio-hypogastric can be easily and safely done. However there are limited studies comparing the truncal nerve block with established techniques ${ }^{[16]}$.

The current concept of management of acute postoperative pain is to use multi-modal approach in the form of combination of multiple drugs or techniques such as combining the regional analgesia, non-opioids, NSAIDs and adjuvants drugs complement each other and minimised side effects of a particular therapy ${ }^{[117-120]}$. Benefit of such approach may be more evident in high risk and elderly compromised patients ${ }^{[121]}$.

\section{Fast tracking protocol/ enhanced recovery after surgery (ERAS) protocol}

The concept of fast tracking is a multi-modal multidisciplinary team approach from the preoperative to postoperative care. With the application of fast tracking or enhanced recovery after surgery protocol that involves team approach to provide early recovery following surgery to improved postoperative outcome including socio-economic benefits ${ }^{[122-125]}$.

\section{Selective Naso-gastric tube:}

Routine use of naso-gastric tube to decompress the stomach is associated with increased risk of pulmonary micro-aspiration and higher rate of pneumonia and atelectasis; it also delays the start of oral intake. Routine use of nasogastric tube in abdominal surgeries is no more indicated ${ }^{[126,127]}$.

\section{Pulmonary physiotherapy}

Patient with pulmonary disease and patient undergoing cardio-thoracic and upper abdominal procedure are at risk of PPC. Lung expansion and respiratory muscle training should ideally be started from the preoperative period and should be continued in the postoperative period as a part of comprehensive treatment ${ }^{[39-42,128,129]}$. Early use of chest physiotherapy in patients with surgery-associated critical illness may have significant impact on physical and functional outcome in addition to decreasing the length of ICU stay ${ }^{[130}$.

\section{Other supportive care}

Proper monitoring in early postoperative period and identification of key events such as desaturation, bradycardia, nausea/vomiting, pain, which are some of the important parameters that are often implicated as predictors of subsequent pulmo-

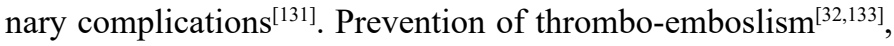
proper nutritional support ${ }^{[134]}$, good glycemic contro[ ${ }^{[135]}$, early recognition and management of infection or sepsis, optimization of fluid and electrolytes balance are important aspect of postoperative patient recovery and outcome.

\section{Summary}

Varieties of PPC may develop in the postoperative period ranging from simple atelectasis to ALI/ARDS in extreme which carries a high mortality. Prevention of PPC is a multidisciplinary multimodal approach involving surgeon, physician, anaesthesiologist, nurse, physiotherapist, dietician etc. Factor implicated for postoperative ALI are grossly divided into patient related, procedure related, anaesthesia related and post procedural care.

PPC can be preventable to a large extent through multi modal approach. Preoperative identification and optimization of high risk preoperative conditions, emphasising for less invasive surgical approach, lung protective anaesthetist strategies, regional analgesia, applying fast tracking protocol and vigilance monitoring and active postoperative care involving multidisciplinary team are important factors in prevention and reduction of PPC. 


\section{References}

1. Jordan, S., Mitchell, J.A., Quinlan, G.J., et al. The pathogenesis of lung injury following pulmonary resection. (2000) Eur Respir J 15(4):790-799.

2. Smetana, G.W. Preoperative Pulmonary evaluation. (1999) N Engl J Med 340(12): 937-944.

3. Cancet, J., Mazo, V. Postoperative pulmonary complications. (2010) Minerva Anestesiol 76(2): 138-143.

4. Ruffini, E, Parola, A., Papalia, E., et al. Frequency and mortality of acute lung injury and acute respiratory distress syndrome after pulmonary resection for bronchogenic carcinoma. (2001) Eur J Cardiothorac Surg 20(1): 30-37.

5. Kutlu, C.A., Williams, E.A., Evans, T.W., et al. Acute lung injury and acute respiratory distress syndrome after pulmonary resection.( 2000) Ann Thorac Surg 69(2): 376-380.

6. Neto, A.S., Hemmes ,S.N., Barbas Carmen, S.V., et al. Incidence of mortality and morbidity related to postoperative lung injury in patients who have undergone abdominal or thoracic surgery: a systematic review and meta-analysis. (2014) The lancet 2(12): 1007-1015.

7. Duggan, M., Kavanagh, B.P. Pulmonary atelectasis: a pathogenic perioperative entity. (2005) Anesthesiology 102(4): 838-854.

8. Arozullah, A.M., Daley, J., Henderson, W.G., et al. Multifactorial risk index for predicting postoperative respiratory failure in men after major noncardiac surgery. The National Veterans Administration Surgical Quality Improvement Program. (2000) Ann Surg 232: 242-253.

9. Aubrun, F., Gazon, M., Schoeffler, M., et al. Evaluation of perioperative risk in elderly patients. (2012) Minerva Anestesiol 78(5): 605-618 10. Coppola, S., Froio, S., Chiumello, D. Protective lung ventilation during general anesthesia: is there any evidence? (2014) Critical care 18(2): 210-217.

11. Hedenstierna, G., Rothen, H.U. Atelectasis formation during anesthesia: causes and measures to prevent it. (2000) J Clin Monit Comput 16(5-6): 329-335

12. Joyce, C.J., Williams, A.B. Kinetics of absorption atelectasis during anesthesia: a mathematical model. (1999) J Appl Physiol 86(4): 1116 1125.

13. Otis, D.R. Jr., Johnson, M., Pedley, T.J., et al. Role of pulmonary surfactant in airway closure: a computational study. (1993) J Appl Physiol 75(3): 1323-1333.

14. Tusman, G., Bohm, S.H., Warner, D.O., et al. Atelectasis and perioperative pulmonary complications in high-risk patients. (2012) Curr Opin Anaesthesiol 25(1):1-10.

15. Arozullah, A.M., Conde, M.V., Lawrence, V.A. Preoperative evaluation for postoperative pulmonary complications. (2003) Med Clin North Am 87(1): 153-173.

16. Djokovic, J.L., Hedley-Whyte, J. Prediction of outcome of surgery and anesthesia in patients over 80. (1979) JAMA 242(21): 2301-2306.

17. Merkow, R.P., Bilimoria, K.Y., McCarter, M.D., et al. Effect of body mass index on short-term outcomes after colectomy for cancer. (2009) J Am Coll Surg 208(1): 53-61.

18. Kuduvalli, M., Grayson, A.D., Oo, A.Y., et al. The effect of obesity on mid-term survival following coronary artery bypass surgery. (2003) Eur J Cardio-thorac Surg 23(3): 368-373.

19. Mendonca, J., Pereira, H., Xara, D., et al. Obese patients: Respiratory complications in the post-anesthesia care unit. (2014) Rev Port Pneumol 20(1): 12-19.

20. Ahmad, S., Nagle, A., McCarthy, R.J., et al. Postoperative hypoxemia in morbidly obese patients with and without obstructive sleep apnea undergoing laparoscopic bariatric surgery. Anesth Analg 2008 107(1): 138-143.

21. Batsis, J.A., Huddleston, J.M., Melton, L.J., et al. Body mass index (BMI) and risk of noncardiac postoperative medical complications in elderly hip fracture patients: a population-based study. (2009) J Hosp Med 4(8): E1-E9.

22. Mustain, W.C., Davenport, D.L., Hourigan, J.S., et al. Obesity and laparoscopic colectomy: outcomes from the ACS-NSQIP database. (2012) Dis Colon Rectum 55(4): 429-435.

23. Demir, A., Aydinli, B., Güçlü, Ç.Y., et al. Obesity and postoperative early complications in open heart surgery. (2012) J Anesth 26(5): 702710 .

24. Launer, H., Nguyen, D.V., Cooke, D.T. National perioperative outcomes of pulmonary lobectomy for cancer in the obese patient: a propensity score matched analysis. (2013) J Thorac Cardiovasc Surg 145(5): 1312-1318.

25. Von Ungern-sternberg, B.S., Regli, A., Schneider, M.C., et al. Effect of obesity and site of surgery on perioperative lung volumes. (2004) Br J Anaesth 92(2): 202-207.

26. Kaw, R., Chung, F., Pasupuleti, V., et al. Meta-analysis of the associated between obstructive sleep apnoea and postoperative outcome. (2012) Br J Anaesth 109(6): 897-906.

27. Smetana, G..W, Lawrence, V.A., Cornell, J.E. Preoperative pulmonary risk stratification for non-cardiothoracic surgery: systemic review for the American College of Physicians. (2006) Ann Intern Med 144(8): 581-595.

28. Licker, M., Schweizer, A., Ellenberger, C., et al. Perioperative medical management of patients with COPD. (2007) Int J Chron Obstruct Pulmon Dis 2(4): 493-515.

29. Warner, M.A., Offord, K.P., Warner, M.E., et al. Role of preoperative cessation of smoking and other factors in postoperative pulmonary complications: a blinded prospective study of coronary artery bypass patients. (1989) Mayo Clin Proc 64(6): 609-616.

30. Theadom, A., Cropley, M. Effects of preoperative smoking cessation on the incidence and risk of intraoperative and postoperative complications in adult smokers: a systematic review. (2006) Tob Control. 15(5): 352-358.

31. Eliasen, M., Gronkjaer, M., Skov-Ettrup, L.S., et al. Preoperative alcohol consumption and postoperative complications: a systematic review and meta-analysis. (2013) Ann Surg 258(6): 930-942.

32. Liu, L.L., Aldrich, J.M., Shimabukuro, D.W., et al. Special article: rescue therapies for acute hypoxemic respiratory failure. (2010) Anesth Analg 111(3): 693-702.

33. Auckley, D., Bolden, N. Preoperative screening and perioperative care of the patient with sleep-disordered breathing. (2012) Curr Opin Pulm Med 18(6): 588-595.

34. Fuster, R.G., Argudo, J.A., Albarova, O.G., et al. Prognostic value of chronic obstructive pulmonary disease in coronary artery bypass grafting. (2006) Eur J Cardiothorac Surg 29(2): 202-209.

35. Sweitzer, B.J., Smetana, G.W. Identification and evaluation of the patient with lung disease. (2009) Anesthesiol Clin 27(4): 673-686.

36. Bingol, H., Cingoz, F., Balkan, A., et al. The effect of oral prednisolone with chronic obstructive pulmonary disease undergoing coronary artery bypasses surgery. (2005) J Card Surg 20(3): 252-256.

37. Starobin, D., Kramer, M.R., Garty, M., et al. Morbidity associated with systemic corticosteroid preparation for coronary artery bypass grafting in patients with chronic obstructive pulmonary disease: a case control study. (2007) J Cardiothorac Surg 2:25.

38. Silvanus, M.T., Groeben, H., Peters, J. Corticosteroids and inhaled salbutamol in patients with reversible airway obstruction markedly decrease the incidence of bronchospasm after tracheal intubation. (2004) Anesthesiology 100(5): 1052-1057.

39. Hulzebos, E.H., Helders, P.J., Favie, N.J., et al. Preoperative intensive inspiratory muscle training to prevent postoperative pulmonary complications in high-risk patients undergoing CABG surgery: a randomized clinical trial. (2006) JAMA 296(15): 1851-1857.

40. Cesario, A., Ferri, L., Galetta, D., et al. Pre-operative pulmonary rehabilitation and surgery for lung cancer. (2007) Lung Cancer 57(1): 118-119.

41. Sekine, Y., Chiyo, M., Iwata, T., et al. Perioperative rehabilitation and physiotherapy for lung cancer patients with chronic obstructive pulmonary disease. (2005) Jpn J Thorac Cardiovasc Surg 53(5): 237-243. 42. Bobbio, A., Chetta, A., Ampollini, L., et al. Preoperative pulmonary rehabilitation in patients undergoing lung resection for non-small cell 
lung cancer. (2008) Eur J Cardiothorac Surg 33(1): 95-98.

43. Bendixen, H.H., Hedley-Whyte, J., Laver, M.B. Impaired oxygenation in surgical patients during general anesthesia with controlled ventilation. A concept of atelectasis. (1963) N Engl J Med 269: 991-996. 44. Kuralay, E., Demírkiliç, U., Öz, B.S., et al. Primary pulmonary hypertension and coronary artery bypass surgery. (2002) J Card Surg 17(1): 79-80.

45. Beck, J.R., Mongero, L.B., Kroslowitz, R.M. et al. Inhaled nitric oxide improves hemodynamics in patients with acute pulmonary hypertension after high-risk cardiac surgery. (1999) Perfusion 14(1): 37-42.

46. Ramakrishna, G., Sprung, J., Ravi, B.S., et al. Impact of pulmonary hypertension on the outcomes of noncardiac surgery: predictors of perioperative morbidity and mortality. (2005) J Am Coll Cardiol 45(10): 1691-1699.

47. Kaw, R., Pasupuleti, V., Deshpande, A., et al. Pulmonary hypertension: an important predictor of outcomes in patients undergoing non-cardiac surgery. (2011) Respir Med 105(4): 619-624.

48. Bhateja, P., Kaw, R., Emerging Risk Factors and Prevention of Perioperative Pulmonary Complications. (2014) Scientific World pp: 546758.

49. Kumar P, Goldstraw P, Yamada K, et al. Pulmonary fibrosis and lung cancer: risk and benefit analysis of pulmonary resection. (2003) J Thorac Cardiovasc Surg 125(6): 1321-1327.

50. Ghatol, A., Ruhl, A.P., Danoff, S.K. Exacerbations in idiopathic pulmonary fibrosis triggered by pulmonary and nonpulmonary surgery: a case series and comprehensive review of the literature. (2012) Lung 190(4): 373-380.

51. Rudra, A., Das, S. Postoperative pulmonary complications. (2006) Indian J Anaesth 50(2): 89-98.

52. Kor, D.J., Lingineni, R.K., Gajic, O., et al. Predicting risk of postoperative lung injury in high-risk surgical patients: a multicenter cohort study. (2014) Anesthesiology 120(5): 1168-1181.

53. Torrington, K.G., Bilello, J.F., Hopkins, T.K., et al. Postoperative pulmonary changes after laparoscopic cholecystectomy. (1996) South Med J 89(7): 675-678.

54. Guller, U., Jain, N., Hervey, S., et al. Laparoscopic vs open colectomy: outcomes comparison based on large nationwide databases. (2003) Arch Surg 138(11): 1179-1186.

55. Vohra, H.A., Whistance, R., Modi, A., et al. Inflammatory response to miniaturised Extracorporeal circulation. A Review of the Literature. (2009) Mediators of Inflammation pp: 707042.

56. Laffey, J.G., Boylan, J.F., Cheng, D.C. The systemic inflammatory response to cardiac surgery: implications for the anaesthesiologist. (2002) Anesthesiology 97(1): 215-252.

57. Berkowitz, D.M., Danai, P.A., Eaton, S., et al. Accurate characterization of extravascular lung water in acute respiratory distress syndrome. (2008) Care med 36(6): 1803-1809.

58. Zupancich, E., paparella, D., Turani, F., et al. Mechanical ventilation affects inflammatory mediators in patients undergoing cardiopulmonary bypass for cardiac surgery: a randomized clinical trial. $2005 \mathrm{~J}$ Thorac Cardiovasc Surg 130(2): 378-383.

59. Karzai, W., Schwarzkopf, K. Hypoxia during one-lung ventilation prediction, prevention and treatment. (2009) Anesthesiology 110(6): 1402-1411.

60. Della Rocca, G., Coccia, C. Ventilatory management of one-lung ventilation. (2011) Minerva Anestesiol 77(5): 534-536.

61. Toy, P., Gajic, O., Bacchetti, P., et al. Transfusion-related acute lung injury: incidence and risk factors. (2012) Blood 119(7): 1757-1767.

62. Rana, R., Fernandez-Perez, E.R., Khan, S.A., et al. Transfusion-related acute lung injury and pulmonary edema in critically ill patients: a retrospective study. (2006) Transfusion 46(9): 1478-1483.

63. McAlister, F.A., Bertsch, K., Man, J., et al. Incidence of and risk factors for pulmonary complications after nonthoracic surgery. (2005) Am J Respir Crit Care Med 171(5): 514-517.

64. Canet, J., Gallart, L. Predicting postoperative pulmonary complications in the general population. (2013) Curr Opin Anaesthesiol 26(2):
107-115.

65. Celli, B.R., Rodriguez, K.S., Snider, G.L. A controlled trial of intermittent positive pressure breathing, incentive spirometry, and deep breathing exercises in preventing pulmonary complications after abdominal surgery. (1984) Am Rev Respir Dis 130(1): 12-15.

66. Yeager, M.P., Glass, D.D., Neff, R.K., et al. Epidural anesthesia and analgesia in high-risk surgical patients. (1987) Anesthesiology 66(6): 729-736.

67. Pedersen, T., Viby-Mogensen, J., Bang, U., et al. Does perioperative tactile evaluation of the train-of-four response influence the frequency of postoperative residual neuromuscular blockade? (1990) Anesthesiology 73(5): 835-839.

68. Rodgers, A., Walker, N., Schug, S., et al. Reduction of postoperative mortality and morbidity with epidural or spinal anaesthesia: results from overview of randomised trials. (2000) BMJ 321(7275):1493.

69. Guarracino, F., Baldassar, R. Perioperative Acute Lung Injury: Reviewing the Role of Anesthetic management. (2012) J Anesthe Clin Res 4: 312-318.

70. Pfitzner, J. Potential for acute lung injury following one-lung ventilation: Alveolar overdistension from partial bronchial obstruction. (2006) Anaesthesia 61(9): 906-907.

71. Gajic, O., Dara, S.I., Mendez, J.L., et al. Ventilator-associated lung injury in patients without acute lung injury at the onset of mechanical ventilation. (2004) Crit Care Medicine 32(9): 1817-1824.

72. Wrigge, H., Pelosi, P. Tidal volume in patients with normal lungs during general anesthesia: lower the better? (2011) Anesthesiology 114(5): 1011-1013.

73. Schultz, M.J., Haitsma J.J., Slutsky A.S., et al. What tidal volumes should be used in patients without acute lung injury? Anesthesiology (2007) 106(6): 1226-1231.

74. Futier, E., Constantin, J.M., Paugam-Burtz, C., et al. A trial of intraoperative low-tidal-volume ventilation in abdominal surgery. (2013) N Engl J Med 369(5): 428-437.

75. Determan, R.M., Royakkers, A., Wolthius, E.K., et al. Influence of low tidal volume ventilation with lower tidal volumes as compared with conventional tidal volumes for patients without acute lung injury: a preventive randomized controlled trial. (2010) Crit Care 14(1): R1.

76. Hemmes SN, Severgnini P, Jaber S, Canet J Wrigge H et al. Rationale and study design of PROVHILO - a worldwide multicenter randomized controlled trial on protective ventilation during general anesthesia for open abdominal surgery. Trials (2011) 12: 111.

77. Wrigge, H., Uhlig, U., Baumgarten, G., Mechanical ventilation strategies and inflammatory responses to cardiac surgery: a prospective randomized clinical trial. (2005) Intensive Care Med 31(10): 13791387.

78. Sundar, S., Novac, V., Jervis, K., et al. Influence of low tidal volume ventilation on time to extubation in cardiac surgical patients. (2011) Anesthesiology 114(5): 1102-1110.

79. Neto, A.S., Cardoso, S.O., Manetta, J.A., et al. Association between use of lung-protective ventilation with lower tidal volumes and clinical outcomes among patients without acute respiratory distress syndrome: a meta-analysis. (2012) JAMA 308(16): 1651-1659.

80. Tao, T., Bo, L., Chen, F., et al. Effect of protective ventilation on postoperative pulmonary complications in patients undergoing general anaesthesia: a meta-analysis of randomised controlled trials. (2014) BMJ Open 4: e005208.

81. Turnage, WS., Lunn, J.L. Postpneumonectomy pulmonary edema. A retrospective analysis of associated variables. Chest (1993) 103: 1646-1650.

82. Goldman, M., Webert, K.E., Arnold D.M., et al. Proceedings of a consensus conference: towards an understanding of TRALI. (2005) Transfus Med Rev 19(1): 2-31.

83. Popovsky, M.A., Moore S.B. Diagnostic and pathogenetic considerations in transfusion-related acute lung injury. (1985) Transfusion 25(6): 573-577.

84. Triulzi, D.J. Transfusion-Related Acute lung Injury: Current Con- 
cepts for the Clinician. (2009) Anesth Analg 108(3): 770-776.

85. Bux, J., Sachs, U.J. The pathogenesis of transfusion-related acute lung injury (TRALI). (2007) Br J Haematol; 136(6): 788-799.

86. Curtis B.R., McFarland, J.G. Mechanisms of transfusion-related acute lung injury (TRALI): Anti-leukocyte antibodies. (2006) Crit Care Med 34(5 Suppl): S118-S123.

87. Swanson, K., Dwyre, D.M., Krochmal, J., et al. Transfusion-related acute lung injury (TRALI): Current clinical and pathophysiologic considerations. (2006) Lung 184(3): 177-185.

88. Toy, P., Popovsky, M.A., Abraham, E., et al. Transfusion-related acute lung injury: Definition and review. 2005 Crit Care Med 33(4): 721-726.

89. Marik., P.E., Corwin, H.L. Acute lung injury following blood transfusion: expanding the definition. (2008) Crit Care Med 36(11): 30803084.

90. Vlaa, A.P., Juffermans, N.P. Transfusion-related acute lung injury: a clinical review. (2013) Lancet 382(9896): 984-994.

91. Brandstrup, B., Tonnesen, H., Beier-Holgersen, R. et al. Effects of intravenous fluid restriction on postoperative complications: comparison of two perioperative fluid regimens: a randomized assessor-blinded multicenter trial. (2003) Ann Surg 238(5): 641-648.

92. Doherty, M., Buggy, D.J. Intraoperative fluids: how much is too much? (2012) BJA 109(1): 69-79.

93. Gurudatt CL. Perioperative fluid therapy: How much is not too much? (2012) Indian J Anaesth 56(4): 323-325.

94. Bundagaard-Nielson, M., Secher, N.H., Kehlet, H. Liberal vs restrictive perioperative fluid therapy - a critical assessment of the evidence (2009) Acta Anaesthesiol Scand 53(7): 843-851.

95. Evans, R.G., Naidu, B. Does a conservative fluid management strategy in the perioperative management of lung resection patients reduce the risk of acute lung injury? (2012) Interact Cardiovasc Thorac Surg 15(3): 498-504.

96. Licker, M., Diaper, J., Villiger, Y. et al. Impact of intraoperative lung-protective interventions in patients undergoing lung cancer surgery. (2009) Crit Care 13(2): R41.

97. Alam, N., Park, B.J., Wilton, A., et al. Incidence and risk factors for lung injury after lung cancer resection. (2007) Ann Thorac Surg 84(4): 1085-1091.

98. Hughes, C,G., Weavind, L., Banerjee, A., et al. Intraoperative risk factors for acute respiratory distress syndrome in critically ill patients. (2010) Anesth Analg 111(2): 464-467.

99. Wei, S., Tian, J., Song, X., et al. Association of perioperative fluid balance and adverse surgical outcomes in esophageal cancer and esophago-gastric junction cancer. (2008) Ann Thorac Surg 86(1): 266272.

100. Fujinga, T., Nakamura, T., Fukuse, T., et al. Isoflurane inhalation after circulatory arrest protects against warm ischemia reperfusion injury of the lungs. (2006) Transplantation 82(9): 1168-1174.

101. Voigtsberger, S., Lachmann, R.A., Leutert, A.C., et al. Sevoflurane ameliorates gas exchange and attenuates lung damage in experimental lipopolysaccharide-induced lung injury. (2009) Anesthesiology 111(6): 1238-1248.

102. De Conno E., Steurer M.P., Wittlinger, M., et al. Anesthetic-induced improvement of the inflammatory response to one-lung ventilation. (2009) Anesthesiology 110(6): 1316-1326.

103. Schilling, T., Kozian, A., Kretzschmar, M., et al. Effects of propofol and desflurane anaesthesia on the alveolar inflammatory response to one-lung ventilation. (2007) Br J Anaesth 99(3): 368-375.

104. Slinger, P. Are lung-protective ventilation strategies worth the effort? South Afr J Anaesth Analg 19(1): 42-50.

105. Bhandari, V., Choo-Wing, R., Lee, C.G., et al. Hyperoxia causes angiopoietin-2 mediated acute lung injury and necrotic cell death. (2006) Nat Med12(11): 1286-1293.

106. Kallet, R.H., Matthay, M.A. Hyperoxic Acute Lung Injury. (2013) Respir Care 58(1): 123-141.

107. Tierney, D,F., Ayres, L., Kasuyama, R,S., et al. Altered sensitivity to O2 toxicity. (1977) Am Rev Respir Dis 115(6): 59-65.

108. Nash, G., Blennerhassett, J.B., Pontoppidan, H. Pulmonary lesions associated with O2 therapy and artificial ventilation. (1967) N Engl J Med. 276(7): 368-374.

109. Cuschieri, R.J., Morran, C.G., Howie, J.C., et al. Postoperative pain and pulmonary complications: comparison of three analgesic regimens. (1985) Br J Surg Jun 72(6): 495-498.

110. Lawrence, V.A., Cornell, J.E., Smetana, G.W., et al. Strategies to reduce postoperative pulmonary complications after noncardiothoracic surgery: systematic review for the American College of Physicians. (2006) Ann Intern Med 144(8): 596-608.

111. Popping, D.M., Elia, N., Marret, E., et al. Protective effects of epidural analgesia on pulmonary complications after abdominal and thoracic surgery: a meta-analysis. (2008) Arch Surg 143(10): 990-999. 112. Wu, CL., Cohen, S.R., Richman. J.M, et al. Efficacy of postoperative patient-controlled and continuous infusion epidural analgesia versus intravenous patient-controlled analgesia with opioids: a meta-analysis. (2005) Anesthesiology 103(5): 1079-1088.

113. Daly, DJ., Myles, P.S. Update on the role of paravertebral blocks for thoracic surgery: are they worth it?. (2009) Curr Opin Anaesthesiol. 22(1): 38-43.

114. Joshi, G.P., Bonnet, F., Shah. R., et al. A systematic review of randomized trials evaluating regional techniques for postthoracotomy analgesia. (2008) Anesth Analg. 107(3): 1026-1040.

115. Messina, M., Boroli, F., Landoni, G., et al. A comparison of epidural vs. paravertebral blockade in thoracic surgery. (2009) Minerva Anestesiol. 75(11): 616-621.

116. Abrahams, M.S., Horn, J.L., Noles, L.M., et al. Evidence-based medicine: ultrasound guidance for truncal blocks. (2010) Reg Anesth Pain med. 35(2 Suppl): S36-S42.

117. Chandrakantan, A., Glass, P.S. Multimodal therapies for postoperative nausea and vomiting, and pain. Br J Anaesth (2011) 107(Suppl 1): i27-i40.

118. Rawlinson, A., Kitchingham, N., Hart, C., et al. Mechanisms of reducing postoperative pain, nausea and vomiting: a systematic review of current techniques. (2012) Evid Based Med 17(3): 75-80.

119. Buvanendran, A., Kroin, J.S. Multimodal analgesia for controlling acute postoperative pain. (2009) Curr Opin Anaesthesiol 22(5): 588593.

120. McDaid, C., Maund, E., Rice, S., et al. Paracetamol and selective and non-selective non-steroidal anti-inflammatory drugs (NSAIDs) for the reduction of morphine-related side effects after major surgery: a systematic review. (2010) Health Technol Assess 14(17) 1-153.

121. Nordquist, D., Halaszynski, T.M. Perioperative Multimodal Anesthesia Using Regional Technique in the Aging Surgical Patient. (2014) Pain Research and Treatment.

122. Feldman, L. S., Baldini, G., Lee, L., et al. Enhanced recovery pathways: Organization of evidence-based, Fast-Track Perioperative Care. Scientific American Surgery.

123. Muehling, B.M., Halter, G.L., Schelzig, H., et al. Reduction of postoperative pulmonary complications after lung surgery using a fast track clinical pathway. (2008) Eur J Cardiothorac Surg 34(1):174-180.

124. Kehlet, H., Wilmore, D.W. Evidence-based surgical care and the evolution of fast-tract surgery. (2008) Ann Surg 248: 189-198.

125. Kehlet, H. Multimodal approach to postoperative recovery. (2009) Curr Opin Crit Care 15(4): 355-358.

126. Lawrence VA, Cornell JE, Smetana GW. Strategies to reduce postoperative pulmonary complications after noncardiothoracic surgery: systematic review for the American College of Physicians. (2006) Ann Intern Med 144(8): 596-608.

127. Nelson, R., Edwards, S., Tse, B. Prophylactic nasogastric decompression after abdominal surgery. (2005) Cochrane Database Syst Rev (1):CD004929.

128. Dronkers, J., Veldman, A., Hoberg, E., et al. Prevention of pulmonary complications after upper abdominal surgery by preoperative intensive inspiratory muscle training: a randomized controlled pilot study. 
(2008) Clin Rehabil 22(2): 134-142.

129. Makhabah, D.N., Martino, F., Ambrosino, N. Perioperative physiotherapy. (2013) Multidiscip Respir Med 8(1): 4.

130. Thomas, A.J. Physiotherapy led early rehabilitation of the patient with critical illness. (2011) Phys Ther Rev 16: 46-57.

131. Weingarten, T.N., Kor, D.J., Gali, B., et al. Predicting postoperative pulmonary complications in high-risk populations. (2013) Curr Opin Anaesthesiol 26(2): 116-125.

132. Gould, M.K., Garcia, D.A., Wren, S.M., et al. Prevention of VTE in nonorthopedic surgical patients: Antithrombotic Therapy and Prevention of Thrombosis, 9th ed: American College of Chest Physicians Evidence-Based Clinical Practice Guidelines. (2012) Chest 141(2 Suppl): e227S-277S.
133. Falck-Ytter, Y., Francis, C.W., Johanson, N.A., et al. Prevention of VTE in orthopedic surgery patients: Antithrombotic Therapy and Prevention of Thrombosis, 9th ed: American College of Chest Physicians Evidence-Based Clinical Practice Guidelines. (2012) Chest 141(2 Suppl): 278S-325S.

134. Lawrence, V.A., Cornell, J.E., Smetana, G.W. Strategies to reduce postoperative pulmonary complications after noncardiothoracic surgery: systematic review for the American College of Physicians. (2006) Ann Intern Med 144(8): 596-608.

135. van den Berghe, G., Wouters, P., Weekers, F., et al. Intensive insulin therapy in the critically ill patients. (2001) N Engl J Med 345(19): 1359-1367. 